\title{
Rap1 GTPase-GDP Dissociation Stimulator
} 1

National Cancer Institute

\section{Source}

National Cancer Institute. Rap1 GT Pase-GDP Dissociation Stimulator 1. NCI Thesaurus.

Code C97760.

Rap1 GT Pase-GDP dissociation stimulator 1 (607 aa, $\sim 66 \mathrm{kDa}$ ) is encoded by the human RAP1GDS1 gene. This protein is involved in the mediation of guanine nucleotide exchange. 